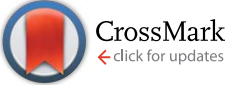

Cite this: RSC Adv., 2017, 7, 15857

\title{
Hierarchical porous MnO/graphene composite aerogel as high-performance anode material for lithium ion batteries $\uparrow$
}

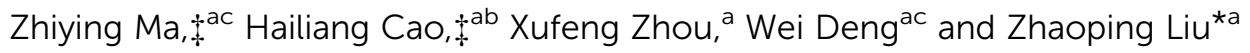

$\mathrm{MnO}$ is a promising anode material for lithium-ion batteries due to its high theoretical capacity and low conversion potential, but it exhibits poor electrical conductivity and volume expansion and hence its practical application is hindered. In this work, we describe a high-conductive and low-expansion $\mathrm{MnO} /$ porous-graphene aerogel (MnO/PGA) hybrid with hierarchical pore structure, which was synthesized by a novel site-localized nanoparticle-induced etching strategy. While graphene network intrinsically guarantees fast electron transfer, it is the characteristic presence of nanosized pores on the graphene sheets that lead to high reversible capacity, favorable rate capability and cycling stability by (i) facilitating the electrolyte infiltration and shortening the diffusion distances of Li-ions, (ii) providing more defects on the graphene sheets to increase the lithium-storage active sites. As a result, the MnO/PGA hybrid exhibits a reversible electrochemical lithium storage capacity as high as $979.6 \mathrm{~mA} \mathrm{~h} \mathrm{~g}$ at $0.5 \mathrm{~A} \mathrm{~g}^{-1}$ after 300 cycles and excellent rate capability of delivering $493.6 \mathrm{~mA} \mathrm{~h} \mathrm{~g}^{-1}$ at a high current density of $2 \mathrm{~A} \mathrm{~g}^{-1}$.

Received 19th January 2017

Accepted 5th March 2017

DOI: $10.1039 / \mathrm{c} 7 \mathrm{ra00818j}$

rsc.li/rsc-advances conductivity and drastic volume variation during the cycling processes, which results in poor rate performance and inferior cycle stability.

To overcome these problems, a suitable matrix is highly desirable to increase the electrical conductivity and buffer the volume change of MnO. In this respect, graphene is an excellent candidate because of its exceptional electrical and mechanical properties, large specific surface area and chemical stability. To date, several preliminary researches about $\mathrm{MnO} /$ graphene composite anode materials have been reported. ${ }^{12-19}$ Among these studies, the sandwich structure in which flexible graphene sheets anchored with transition metal oxides form layered structure is favored by many researchers. ${ }^{11,15-21}$ For example, Song et al. synthesized MnO-nanowire/graphene composite with a sandwich-like structure and reported a reversible lithium storage capacity of $930 \mathrm{~mA} \mathrm{~h} \mathrm{~g}{ }^{-1}$ after 500 cycles at $0.5 \mathrm{~A} \mathrm{~g}^{-1} .^{15}$ Zhang and coworkers reported a reversible lithium storage capacity as high as $772 \mathrm{~mA} \mathrm{~h} \mathrm{~g}^{-1}$ at $100 \mathrm{~mA} \mathrm{~g}^{-1}$ after 90 cycles for a nitrogen-doped $\mathrm{MnO} /$ graphene hybrid with a similar sandwich structure. ${ }^{11}$ Even though the $\mathrm{MnO} /$ graphene composites with different sandwich-like structures have shown a good prospect in high-capacity LIBs, their disadvantages in Li-ion storage cannot be neglected. For example, the closely packed architecture would hinder the electrolyte infiltration, intrinsically limiting mass transfer. Furthermore, MnO particles distributed on the graphene layers are likely to increase the contact resistance between graphene nanosheets, which would limit the fast electron transfer as well as aggravate the polarization of electrode at high current densities. Therefore, the design of $\mathrm{MnO} /$ graphene composite with novel nanostructure is necessary to solve these defects. 
In recent years, assembly of $2 \mathrm{D}$ graphene sheets into $3 \mathrm{D}$ architecture has obtained researchers' favor due to the excellent mechanical, electrical and thermal properties of $3 \mathrm{D}$ porous grapheme. ${ }^{22-27}$ But the large graphene sheets may increase the transport distance of Li-ions inside the active materials. Therefore some researchers have attempted to create nanoholes on the graphene sheets to address this issue. ${ }^{28-34}$ For example, Fan et al. synthesized porous graphene nanosheets (PGs) using the etching strategy, which showed excellent rate capability due to its open layered and mesoporous structure that facilitated efficient access of electrolytes to the electrode material and shortened the ion diffusion pathway through the porous sheets. ${ }^{32}$ Our group has also successfully fabricated 3D monolithic PG/Co hybrid aerogel with high gravimetric/volumetric capacity as a compressible anode for LIBs and site-localized nanoparticle-induced etching strategy was proposed for the formation of nanopores on graphene sheets. ${ }^{34}$ Therefore, PG sheets as building blocks for construction of large-scale 3D frameworks with hierarchical pore distributions provide a unique platform for design and development of novel composite anode materials. Specifically for $\mathrm{MnO}$, the PG network allows fast mass transport through their hierarchically arranged pores and provides three dimensional electron transport pathways. In addition, the open porous structure of PG network can offer abundant space to buffer volume expansion of MnO during charge and discharge processes. To the best of our knowledge, there have been no reports of the controllable assembly of MnO nanoparticles supported on 3D PG networks as anode materials.

In this work, monolithic $\mathrm{MnO} /$ porous-graphene aerogel (MnO/PGA) composite anode material was fabricated via a combined process of hydrothermal self-assembly, freezedrying and annealing. During annealing, uniform MnO nanoparticles and nanopores on the graphene were simultaneously generated through a site-localized nanoparticle-induced etching strategy. ${ }^{34}$ In contrast to previous reports on graphene-supported composites with sandwich structure, $\mathrm{MnO}$ / PGA composites demonstrate 3D interconnected macroporous architecture with uniform deposition of MnO nanoparticles and distribution of nanopores (50-100 nm), which provides highly conductive networks with enhanced surface area and short diffusion lengths for lithium ions. As a result, MnO/PGA exhibits outstanding reversible capacity and excellent rate performance (979.6 $\mathrm{mA} \mathrm{h} \mathrm{g}^{-1}$ after 300 cycles at a chargedischarge rate of $0.5 \mathrm{~A} \mathrm{~g}^{-1}$ and reversible discharge capacity of $493 \mathrm{~mA} \mathrm{~h} \mathrm{~g}^{-1}$ at $2 \mathrm{~A} \mathrm{~g}^{-1}$ ), when employed as the anode material for LIBs.

\section{Experimental}

\section{Materials preparation}

Graphite oxide was synthesized from natural graphite flakes (50 $\mu \mathrm{m})$ following a modified Hummers method. ${ }^{35}$ To prepare the graphene oxide (GO) solution, the obtained graphite oxide was dispersed in water by sonication for $15 \mathrm{~min}$, reaching a concentration of $2 \mathrm{mg} \mathrm{mL}{ }^{-1} .30 \mathrm{~mL}$ of homogeneous GO aqueous dispersion was sealed in a cylindrical vessel and maintained at $180{ }^{\circ} \mathrm{C}$ for $12 \mathrm{~h}$. Then the autoclave was naturally cooled to room temperature. The resulting graphene hydrogel was immersed in $\mathrm{Mn}\left(\mathrm{NO}_{3}\right)_{2}$ solution $\left(50 \mathrm{mg} \mathrm{mL}{ }^{-1}\right.$ ) for $6 \mathrm{~h}$ to absorb the $\mathrm{Mn}^{2+}$ adequately via electrostatic interaction. Then the hydrogel was taken out and directly dehydrated via a freezedrying process to maintain the 3D monolithic architecture. Finally, the MnO/PGA composite was fabricated by annealing the dehydrated aerogel at $850{ }^{\circ} \mathrm{C}$ for $2 \mathrm{~h}$ in Ar atmosphere.

For comparison, bare graphene aerogel (GA) was also prepared by annealing the raw graphene oxide aerogel in the same condition. The pure $\mathrm{MnO}$ was obtained by annealing the $\mathrm{Mn}\left(\mathrm{CH}_{3} \mathrm{COO}\right)_{2}$ particles directly at $850{ }^{\circ} \mathrm{C}$ for $2 \mathrm{~h}$. And $\mathrm{MnO} /$ graphene aerogel (MnO/GA) composite with no nanoholes on graphene sheets was prepared by the similar procedure in which the graphene hydrogel was immersed in the $\mathrm{Mn}\left(\mathrm{CH}_{3}-\right.$ $\mathrm{COO})_{2}$ solution.

\section{Materials characterization}

Powder X-ray diffraction (XRD) patterns were recorded on a D8 $\mathrm{X}$-ray diffractometer using $\mathrm{Cu}-\mathrm{K} \alpha$ irradiation $(\lambda=1.5406 \AA)$ at 40 $\mathrm{kV}, 20 \mathrm{~mA}$ over the $2 \theta$ range from 10 to $80^{\circ}$. The microstructure of the samples was characterized by field-emission scanning electron microscope (SEM, FEI, Sirion 200) and transmission electron microscope (TEM, JEOL 2100F). Thermogravimetric and differential thermal analyses (TG/DTA) were performed with a PerkinElmer Diamond TG/DTA apparatus at a heating rate of $10{ }^{\circ} \mathrm{C} \mathrm{min}^{-1}$ in flowing air. Raman spectra were measured on a Renishaw Invia spectrometer using a laser of $514.5 \mathrm{~nm}$ at room temperature. Nitrogen adsorption-desorption isotherms were recorded at $77 \mathrm{~K}$ using a Micrometritics ASAP 2020 analyzer.

\section{Electrochemical measurements}

For preparing working electrodes, a mixture of active material (80 wt\%), polyvinylidene difluoride (binder, $10 \mathrm{wt} \%$ ) and super P (10 wt $\%)$ dispersed in $N$-methyl-2-pyrrolidinone (NMP) was coated on the nickel-foam $\left(c a .1 .3 \mathrm{~cm}^{2}\right)$ and dried at $80^{\circ} \mathrm{C}$ in vacuum for $6 \mathrm{~h}$ before pressing. The mass of the active component for each plate was about 2-3 mg. The electrochemical performance of the active material was evaluated via CR2032 type coin cells with a pure lithium foil as the counter electrode, Celgard 2300 as the separator, and $1 \mathrm{M} \mathrm{LiPF}_{6}$ in a mixture of ethylene carbonate (EC) and dimethyl carbonate (DMC) $(\mathrm{v} / \mathrm{v}=1: 1)$ as the electrolyte. The cells were assembled in an argon-filled glove box with concentrations of moisture and oxygen below $1.0 \mathrm{ppm}$. After assembling, the cells were charged and discharged in Land CT 2001A system at various current densities in the voltage range of 0.01 to $3.0 \mathrm{~V}$. Cyclic voltammograms (CV) were measured on a Solartron 1400 workstation with the testing voltage between 0.01 and $3.0 \mathrm{~V}$ at a scan rate of $0.1 \mathrm{mV} \mathrm{s}^{-1}$. The electrochemical impedances spectroscopy (EIS) of active material was recorded on an electrochemical workstation (Solartron 1400) using the frequency response analysis. The impedance spectra were obtained by applying a sine wave with amplitude of $5.0 \mathrm{mV}$ over the frequency range from 100 $\mathrm{kHz}$ to $0.01 \mathrm{~Hz}$. 


\section{Results and discussion}

\section{Materials synthesis and characterization}

The synthetic route of MnO/PGA is illustrated in Fig. 1. First, GO sheets were self-assembled into a 3D hydrogel via a hydrothermal method. Second, the hydrogel was immersed in $\mathrm{Mn}\left(\mathrm{NO}_{3}\right)_{2}$ solution for $6 \mathrm{~h}$, during which $\mathrm{Mn}^{2+}$ ions diffused into the hydrogel due to the concentration difference and were attracted to the surface of graphene sheets via electrostatic interaction. Third, the graphene hydrogel attached with $\mathrm{Mn}^{2+}$ was directly dehydrated via a freeze-drying process to maintain the 3D monolithic architecture. Then the as-obtained aerogel is heat treated at a high temperature of $850{ }^{\circ} \mathrm{C}$ for $2 \mathrm{~h}$ under $\mathrm{Ar}$ atmosphere to synthesize the MnO/PGA hybrid. During the annealing process, $\mathrm{Mn}\left(\mathrm{NO}_{3}\right)_{2}$ was initially transformed to $\mathrm{Mn}_{3} \mathrm{O}_{4}$, which then reacted with carbon atoms in graphene to form $\mathrm{MnO}$ nanocrystals and generate nano-sized holes on the graphene sheets simultaneously, following the reaction equation of $\mathrm{Mn}_{3} \mathrm{O}_{4}+\mathrm{C} \rightarrow \mathrm{MnO}+$ $\mathrm{CO} .{ }^{19}$ For comparison, $\mathrm{MnO} / \mathrm{GA}$ hybrid without pores on graphene sheets was also prepared by using $\mathrm{Mn}\left(\mathrm{CH}_{3} \mathrm{COO}\right)_{2}$ as the precursor instead of $\mathrm{Mn}\left(\mathrm{NO}_{3}\right)_{2}$, as $\mathrm{Mn}\left(\mathrm{CH}_{3} \mathrm{COO}\right)_{2}$ decomposed into $\mathrm{MnO}$ directly during annealing. ${ }^{16}$ Bare $\mathrm{MnO}$ and bare GA were also synthesized for comparison.

XRD patterns of the MnO/PGA, MnO/GA and pure MnO are shown in Fig. 2a. The characteristic peaks of the bare $\mathrm{MnO}$ can be indexed to a cubic phase MnO (JCPDS no.78-0230). ${ }^{15,16}$ All strong peaks of the $\mathrm{MnO} / \mathrm{PGA}$ and $\mathrm{MnO} / \mathrm{GA}$ hybrid materials are consistent with the bare $\mathrm{MnO}$ and a weak peak at around $26^{\circ}$ is in accordance with the characteristic peak of the (002) plane of graphene. As we can see from the XRD patterns, MnO/GA and MnO/PGA hybrids own the same components even though their precursors are different before annealing. However the peak intensity of $\mathrm{MnO}$ phase in $\mathrm{MnO} / \mathrm{PGA}$ sample is weaker than that in $\mathrm{MnO} / \mathrm{GA}$ and the full width of peaks at half-maximum in MnO/PGA becomes broader comparing with that in MnO/GA. The difference is caused by the size variation of $\mathrm{MnO}$ particles on graphene sheets when using different manganese precursors, which will be further confirmed later by other analysis methods. TGA measurement carried out in the air is used to determine the content of $\mathrm{MnO}$ in $\mathrm{MnO} / \mathrm{PGA}$ and $\mathrm{MnO} / \mathrm{GA}$ hybrid. As shown in Fig. 2b, the two TGA curves are similar, both of which display a slight weight increase from $200{ }^{\circ} \mathrm{C}$ to $400{ }^{\circ} \mathrm{C}$, corresponding to oxidation of $\mathrm{MnO}$ to $\mathrm{Mn}_{2} \mathrm{O}_{3}$ in air. Then a significant weight loss from $400{ }^{\circ} \mathrm{C}$ to $500{ }^{\circ} \mathrm{C}$ occurs,
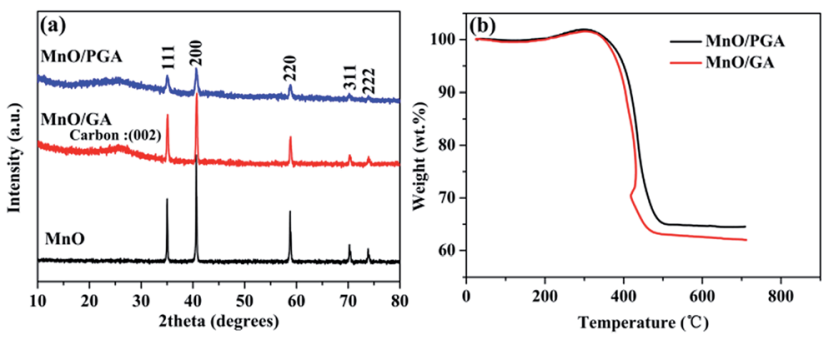

Fig. 2 (a) XRD patterns of $\mathrm{MnO} / \mathrm{PGA}, \mathrm{MnO} / \mathrm{GA}$ and $\mathrm{MnO}$ samples. (b) TGA curves of $\mathrm{MnO} / \mathrm{PGA}$ and $\mathrm{MnO} / \mathrm{GA}$ samples.

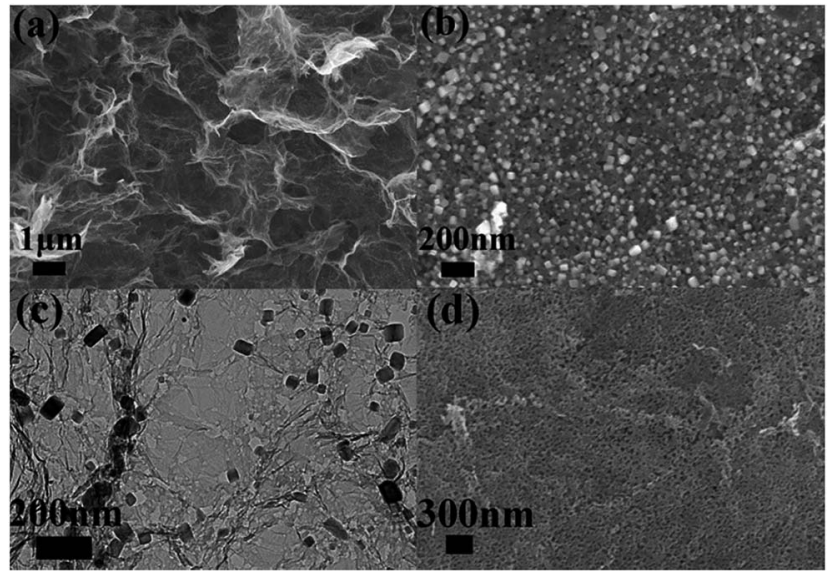

Fig. 3 (a and b) Typical SEM images with different magnifications of $\mathrm{MnO} / \mathrm{PGA}$ hybrid. (c) TEM image of MnO/PGA composite. (d) SEM image of the residue of $\mathrm{MnO} / \mathrm{PGA}$ after washing with $\mathrm{HCl}$.

which is contributed by the combustion of graphene. The weight of both samples becomes steady above $500{ }^{\circ} \mathrm{C}$, suggesting that only thermally stable $\mathrm{Mn}_{2} \mathrm{O}_{3}$ remains..$^{15,16,18}$ Hence the weight proportions of $\mathrm{MnO}$ in two hybrids are calculated to be $56.4 \%(\mathrm{MnO} / \mathrm{GA})$ and 59.1\% (MnO/PGA), respectively.

The morphology and microstructure of MnO/PGA hybrid were investigated by field-emission scanning electron microscopy (FE-SEM) and transmission electron microscopy (TEM). As shown in Fig. 3a, the MnO/PGA hybrid maintains an integrated 3D network with continuous pores of several micrometers, which is similar to typical bare GA. Furthermore in the SEM image of $\mathrm{MnO} / \mathrm{PGA}$ with higher magnification (Fig. 3b), it can be seen that the MnO particles, which are around $50-100 \mathrm{~nm}$ in

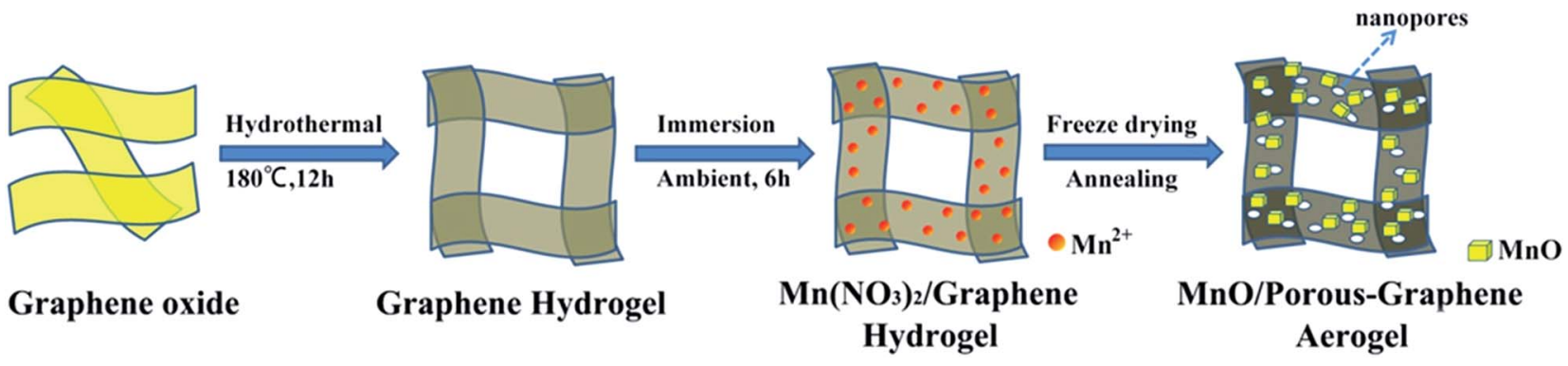

Fig. 1 Schematic illustration of the synthesis route of MnO/PGA. 
size, are anchored on the graphene sheets uniformly, and some holes are also obvious around these nanoparticles. Fig. 3c exhibits a TEM image for the MnO/PGA sample. Cubic MnO nanoparticles are well attached to the wrinkled porous graphene sheets and the nanopores keep a similar morphology as MnO particles, which further verifies the etching mechanism. After removing $\mathrm{MnO}$ nanoparticles by $\mathrm{HCl}$, a large amount of nanoholes homogenously distributing on the thin graphene layers are clearly seen (Fig. 3d). These results indicate that $\mathrm{MnO}$ / PGA hybrid can be effectively produced by site-localized nanoparticle-induced etching strategy at proper annealing condition.

For comparison, bare $\mathrm{MnO}$ and $\mathrm{MnO} / \mathrm{GA}$ composite were also prepared by the similar procedure. Fig. 4a shows that bare MnO particles prepared by direct thermal decomposition of $\mathrm{Mn}\left(\mathrm{CH}_{3} \mathrm{COO}\right)_{2}$ have sizes around several hundreds of nanometers. Moreover, the agglomeration is severe among $\mathrm{MnO}$ particles. Fig. 4b displays the SEM image of MnO/GA hybrid in which $\mathrm{MnO}$ particles ranging from 150 to $200 \mathrm{~nm}$ distribute on the graphene sheets, and graphene sheets form a 3D network. As we can see that the sizes of MnO particles have a remarkable decrease with the introduction of graphene sheets comparing to bare MnO. The same phenomenon can also be observed in other reports. ${ }^{5-11}$ However MnO particles in MnO/PGA hybrid have the smallest size among three samples, which should be ascribed to the site-localized nanoparticle-induced etching strategy. Moreover, no nanopores around $\mathrm{MnO}$ particles can be found in the SEM (Fig. 4c) and TEM images (Fig. 4d) of MnO/GA composite. This is because during annealing, $\mathrm{Mn}\left(\mathrm{CH}_{3} \mathrm{COO}\right)_{2}$ decomposes to $\mathrm{MnO}$ directly at low temperature, and $\mathrm{MnO}$ is inert in Ar atmosphere, which can't react with carbon at high temperature. , $^{\mathbf{1 6}}$

The nitrogen adsorption/desorption study was used to test the GA, MnO/GA and MnO/PGA. The specific surface area of $\mathrm{MnO} / \mathrm{PGA}$ is $439.3 \mathrm{~m}^{2} \mathrm{~g}^{-1}$, which is much higher than that of pristine GA $\left(271.53 \mathrm{~m}^{2} \mathrm{~g}^{-1}\right)$. The specific surface area of $\mathrm{MnO} /$ GA $\left(249.8 \mathrm{~m}^{2} \mathrm{~g}^{-1}\right)$ is similar to that of pristine GA $\left(271.53 \mathrm{~m}^{2}\right.$ $\mathrm{g}^{-1}$ ), which suggests that the enlarged surface area of MnO/PGA

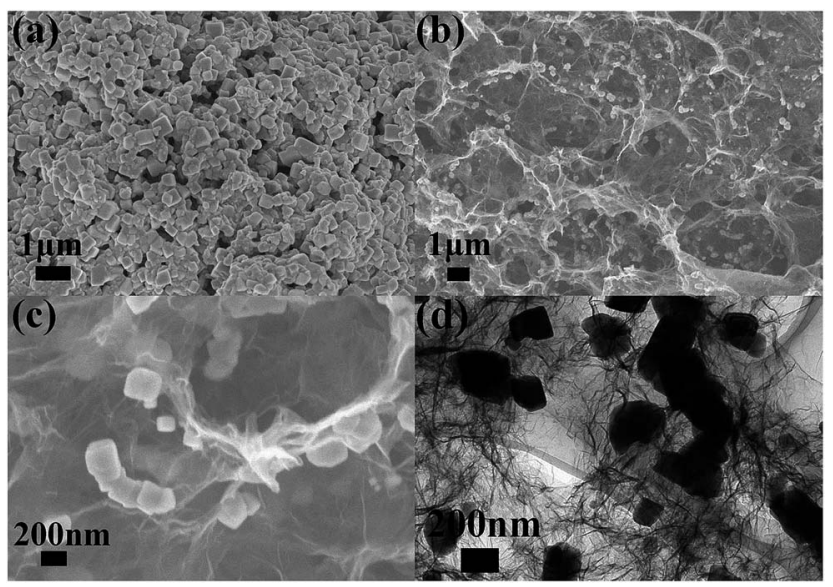

Fig. 4 (a) Typical SEM image of bare $\mathrm{MnO}$. (b and c) SEM images with different magnifications of MnO/GA composite. (d) TEM image of $\mathrm{MnO} / \mathrm{GA}$ composite. is mainly induced by the nanopores on the graphene sheets. The pore size distribution of three sampels (Fig. S1†) were also estimated by BJH method. Comparing with bare GA, the existence of macropores ( $c a .50-70 \mathrm{~nm}$ ) for MnO/PGA also confirms the formation of nanopores on graphene by etching. The Raman spectra (Fig. 5b) were also recorded to investigate the structure changes from GA to MnO/PGA. The high intensity of the $\mathrm{D}$ band indicates the presence of defects in the MnO/PGA hybrid. The intensity ratio of the $\mathrm{D}$ band to the $\mathrm{G}$ band $\left(I_{\mathrm{D}} / I_{\mathrm{G}}\right)$ of the $\mathrm{MnO} / \mathrm{PGA}$ is 1.08 , whereas 0.97 and 1.05 for $\mathrm{GA}$ and $\mathrm{MnO} /$ $\mathrm{GA}$, respectively. For $\mathrm{MnO} / \mathrm{PGA}$, the high $I_{\mathrm{D}} / I_{\mathrm{G}}$ value may be ascribed to more defects due to the nanopores in the graphene sheets, which is in good agreement with SEM and TEM results.

\section{Electrochemical performance}

To understand the electrochemical performance of the $\mathrm{MnO} /$ PGA composite as anode material for LIBs, the cyclic voltammetry (CV) curves for the initial three cycles were tested at a scan rate of $0.1 \mathrm{mV} \mathrm{s}^{-1}$ in the voltage range of $0.01-3 \mathrm{~V}$. In the first cycle, an irreversible reduction peak at around $0.6 \mathrm{~V}$ corresponds to the formation of a solid electrolyte interface (SEI) layer, and the weak peak located at $c a$. 1.5-1.2 $\mathrm{V}$ may be attributed to the reduction of the electrolyte. The large reduction peak at about $0.2 \mathrm{~V}$ in the first cycle can be ascribed to the complete reduction of $\mathrm{Mn}^{2+}$ to $\mathrm{Mn}^{0}$. And the reduction peak of $\mathrm{Mn}^{2+}$ to $\mathrm{Mn}^{0}$ is shifted to $c a .0 .50 \mathrm{~V}$ in the subsequent cycles due to the improved kinetics of the MnO/PGA electrode after first lithiation. The main anodic peak is located at $c a$. $1.20 \mathrm{~V}$, corresponding to the oxidation of $\mathrm{Mn}^{0}$ to $\mathrm{Mn}^{2+}$, and the weak and broad peak at around $2.10 \mathrm{~V}$ is associated with the oxidation of $\mathrm{Mn}^{2+}$ to a higher oxidation state. ${ }^{16}$ Importantly, after the first cycle, the subsequent $\mathrm{CV}$ curves are almost overlapped, proving that a stable SEI layer is generated on the surface of the hybrid and the structural integrity of the small MnO particles is maintained, thereby leading to excellent reversibility of the MnO/PGA electrode.

Fig. $6 \mathrm{~b}$ presents the first discharge and charge curves of bare $\mathrm{MnO}, \mathrm{MnO} / \mathrm{GA}$, and $\mathrm{MnO} / \mathrm{PGA}$ at $50 \mathrm{~mA} \mathrm{~g}^{-1}$ within a cut-off voltage window between 0.01 and $3 \mathrm{~V}$. In the first cycle, bare $\mathrm{MnO}$ anode shows an initial reversible specific capacity of 623

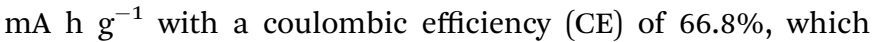
coincides with the related reports. ${ }^{5,18}$ The capacity loss is mainly attributed two points. Much of irreversible $\mathrm{Li}^{+}$is consumed to form the SEI layer and the poor electrical conductivity of bare
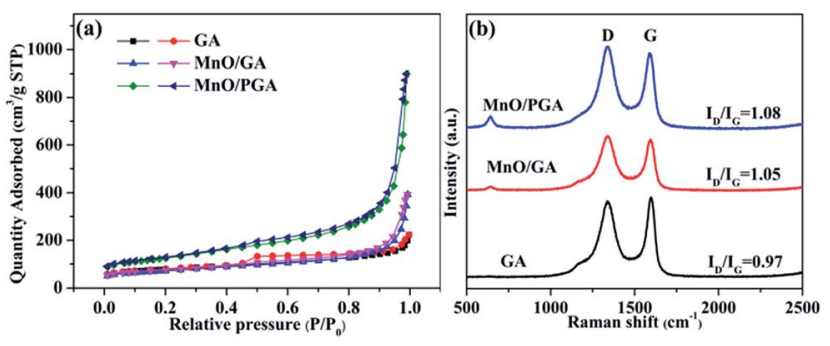

Fig. 5 (a) Nitrogen adsorption/desorption isotherms (b) Raman spectra of $\mathrm{GA}, \mathrm{MnO} / \mathrm{GA}$ and $\mathrm{MnO} / \mathrm{PGA}$ samples. 

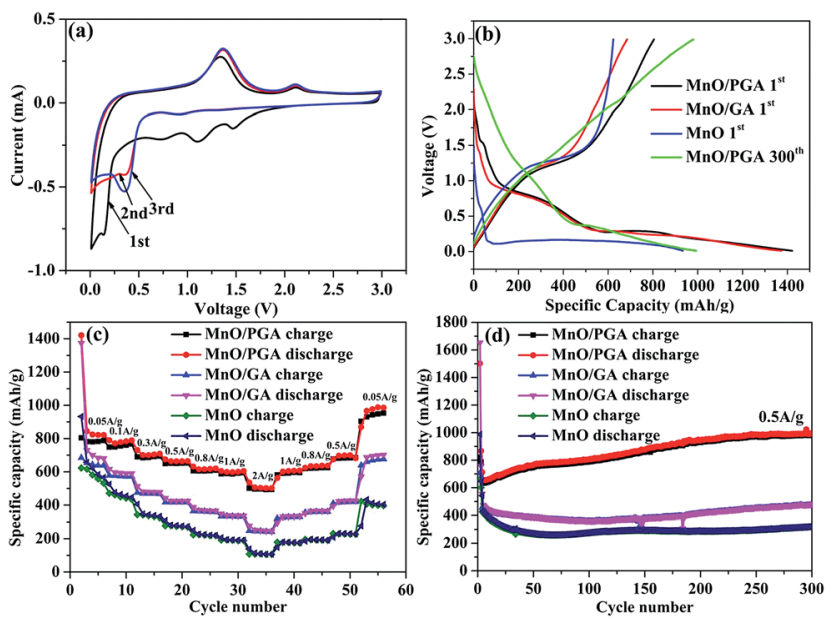

Fig. 6 (a) CV profiles of the MnO/PGA sample. (b) The initial chargedischarge profiles of different samples (MnO/PGA, MnO/GA and bare $\mathrm{MnO}$ ) at $0.05 \mathrm{~A} \mathrm{~g}^{-1}$, the 300 th cycle of $\mathrm{MnO} / \mathrm{PGA}$ at $0.5 \mathrm{~A} \mathrm{~g}^{-1}$. (c) Rate capability of different samples. (d) Cycle performance of different samples at $0.5 \mathrm{~A} \mathrm{~g}^{-1}$

$\mathrm{MnO}$ also hampers the conversion from $\mathrm{Li}_{2} \mathrm{O}$ to $\mathrm{Li}^{+}$in the first charge process, resulting in low initial reversible capacity releasing. At the same current density, $\mathrm{MnO} / \mathrm{GA}$ reveals a reversible capacity of $684.7 \mathrm{~mA} \mathrm{~h} \mathrm{~g}^{-1}$ with a low CE of $49.8 \%$, whereas MnO/PGA delivers a specific discharge capacity of 1421.4 $\mathrm{mA} \mathrm{h} \mathrm{g}^{-1}$ and charge capacity of $804.6 \mathrm{~mA} \mathrm{~h} \mathrm{~g}^{-1}$ with a relatively higher $\mathrm{CE}$ of $56.6 \%$. The increased capacity of two hybrids compared with bare MnO may be attributed to the graphene sheets which can accelerate the electron transfer in electrode. However the lower CE of two hybrids is also because of the graphene sheets, which is an inherent phenomenon for carbon materials with large surface area. By contrast, MnO/PGA displays a better electrochemical performance than MnO/GA. This should be ascribed to the advantages of MnO/PGA hybrid as following: (i) the hierarchical porous structure which makes the electrolyte infiltrate into monolithic electrode adequately and provides more active sites and edges for faster electron transport, guarantees that the electrochemical activity of $\mathrm{MnO}$ could be exploited availably during the first cycle; (ii) the lithium-storage active sites of graphene sheets increase due to more defects generated by nanopores, leading to higher reversible capacity obtained than pristine graphene. And it was found that the charge curves of $\mathrm{MnO} / \mathrm{GA}$ and MnO/PGA hybrids begin to diverge above $0.5 \mathrm{~V}$, which implies that the increased capacity are partly from the defects, such as pores or the edge sites of grapheme; ${ }^{36}$ (iii) the sizes of $\mathrm{MnO}$ particles $(50-100 \mathrm{~nm}$ ) are smaller than those in the MnO/GA hybrid (150-200 nm), which enhances the electrochemical activity of $\mathrm{MnO}$ particles owing to their higher specific surface area.

The rate performance of electrode materials is a very important parameter for their applications. As shown in Fig. 6c, the $\mathrm{MnO} / \mathrm{PGA}$ presents evidently higher capacity than bare $\mathrm{MnO}$ or $\mathrm{MnO} / \mathrm{GA}$ electrode under all investigated current densities (0.05-2 $\left.\mathrm{A} \mathrm{g}^{-1}\right)$. Based on the initial charge capacity at $0.05 \mathrm{~A} \mathrm{~g}^{-1}$, the capacity retention of $\mathrm{MnO} / \mathrm{PGA}, \mathrm{MnO} / \mathrm{GA}$ and $\mathrm{MnO}$ electrodes at $2 \mathrm{~A} \mathrm{~g}^{-1}$ is calculated to be $61.3 \%, 35.3 \%$ and $17 \%$, respectively. The charge-discharge curves (Fig. S2 $\dagger$ ) demonstrate slow decay of the reversible capacity and slow decline of the voltage plateau of $\mathrm{MnO} / \mathrm{PGA}$ with the increase of the current, also suggesting good rate capability. As far as we know, such excellent rate performance has barely been achieved in previous studies of $\mathrm{MnO} /$ graphene composites, which should be largely ascribed to the PG network with hierarchical pore structure. Not only could the 3D interconnected GA substrate facilitate the electrolyte infiltration and the transfer of ions and charges, but also the nanopores on the graphene sheets provide abundant pathways for the fast Li-ion transport under high current densities. Furthermore, the sizes of MnO are controlled in a small dimension in the MnO/PGA sample via a sitelocalized nanoparticle-induced etching strategy, which generates more exposed active sites to achieve rapid charge and discharge of $\mathrm{MnO} / \mathrm{PGA}$. It is worth noting that when the current density is changed back to $0.05 \mathrm{~A} \mathrm{~g}^{-1}$, the reversible capacity of $\mathrm{MnO} / \mathrm{PGA}$ rises to $876 \mathrm{~mA} \mathrm{~h} \mathrm{~g}^{-1}$, which is even higher than the initial capacity ( $804.6 \mathrm{~mA} \mathrm{~h} \mathrm{~g}^{-1}$ ), demonstrating that the 3D PG network can maintain structure integrity of the electrode.

In addition to the rate performance, the cycle performance is also measured to determine the structure stability of samples during cycling (Fig. 6d). MnO/PGA displays an initial reversible capacity of $635.5 \mathrm{~mA} \mathrm{~h} \mathrm{~g}^{-1}$ at $0.5 \mathrm{~A} \mathrm{~g}^{-1}$, then the specific capacity has a slight decline from $635.5 \mathrm{~mA} \mathrm{~h} \mathrm{~g}^{-1}$ to $630 \mathrm{~mA} \mathrm{~h} \mathrm{~g}^{-1}$ in the next 10 cycles. Surprisingly, the gravimetric capacity rises to 979.6 $\mathrm{mA} \mathrm{h} \mathrm{g}^{-1}$ after subsequent 290 cycles, which is even higher than the theoretical capacity of $\mathrm{MnO}\left(755 \mathrm{~mA} \mathrm{~h} \mathrm{~g}^{-1}\right)$. Similar results have been reported for many other $\mathrm{MnO}$ / graphene composite anodes. ${ }^{\mathbf{1 5 , 1 6 , 3 7 - 3 9}}$ It has been confirmed that $\mathrm{Mn}^{2+}$ ions could be further oxidized to a higher oxidation state in well-designed $\mathrm{MnO} /$ graphene composites. ${ }^{\mathbf{1 6}}$ By investigating the charge-discharge curves of MnO/PGA electrode at different cycle numbers (Fig. S3†), it is found that the charge curves before $c a .1 .5 \mathrm{~V}$ at different cycles almost overlap, while the curves after $1.5 \mathrm{~V}$ gradually flatten and elongate to higher specific capacities along with cycling, indicating an everincreasing capacity and $\mathrm{Li}^{+}$reactivity. An obvious charge plateau at around $2.10 \mathrm{~V}$ can be clearly observed after the $200^{\text {th }}$ cycle, implying a higher oxidation state $(>2)$ of manganese in the end product. ${ }^{38}$ For the MnO/PGA composite, the 3D graphene network intrinsically guarantees fast electron transfer, and the nanopores on the graphene sheets facilitate the electrolyte infiltration and shorten the diffusion distances of Li-ions, both of which are beneficial for the improvement of the reaction kinetics between $\mathrm{MnO}$ and $\mathrm{Li}^{+}$, resulting that much higher state of $\mathrm{Mn}$ is obtained gradually during cycling. Thus, it is reasonable that $\mathrm{Mn}^{2+}$ ions in the MnO/PGA electrode can be oxidized to a higher oxidation state during long-term cycling, resulting in gradual increase of the specific capacity. Nevertheless, this phenomenon was not found in the charge curve of bare $\mathrm{MnO}$ and it displays poor cyclability with low capacity. Actually, the cycling curve of $\mathrm{MnO} / \mathrm{GA}$ shows a similar tendency as MnO/PGA but it goes through a longer declining process than MnO/PGA. It is probably because the $\mathrm{MnO}$ particles on the graphene sheets are pulverized and dissolved into the electrolyte during the first 


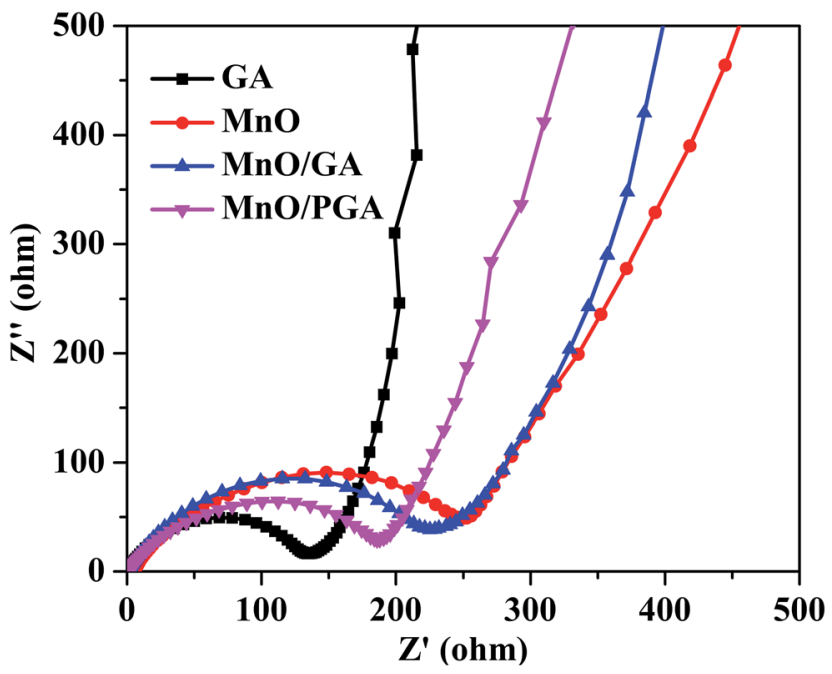

Fig. 7 EIS spectra of the pristine $\mathrm{GA}$, bare $\mathrm{MnO}, \mathrm{MnO} / \mathrm{GA}$ and $\mathrm{MnO} /$ PGA hybrid.

150 cycles, leading to the decline of the specific capacity. After following 150 cycles, the reversible capacity of $\mathrm{MnO} / \mathrm{GA}$ increases to $475.8 \mathrm{~mA} \mathrm{~h} \mathrm{~g}{ }^{-1}$ gradually, indicating that the $\mathrm{MnO}$ particles are controlled within a reasonable size. To further confirm the structural integrity of MnO/PGA hybrid, its morphology (Fig. S4†) after continuous cycles was studied. The $3 \mathrm{D}$ porous graphene network is well preserved after 50 cycles at $0.05 \mathrm{~A} \mathrm{~g}^{-1}$, and the nanopores on the graphene sheets can also be detected obviously. Meanwhile, MnO nanoparticles are still uniformly attached to the graphene sheets, and their particle sizes remains almost the same as the ones before cycling. These results indicate that the structural integrity of $\mathrm{MnO} / \mathrm{PGA}$ electrode can be well maintained during cycling, thereby leading to excellent cycling stability.

To verify the superior electrochemical performance of $3 \mathrm{D}$ MnO/PGA electrode, AC impedance measurements are carried out in the initial cycle, and the results are displayed in Fig. 7. As we can see, the diameter of the semicircle for MnO/PGA in the high-medium frequency region is much smaller than that of $\mathrm{MnO} / \mathrm{GA}$, suggesting that MnO/PGA possesses lower contact and charge transfer resistance. Furthermore, it can be concluded that the diffusion impedance of lithium ions in the $\mathrm{MnO} / \mathrm{PGA}$ electrode is lower than other electrodes from the lowfrequency linear part, indicating that the nanopores on the graphene sheets provide abundant pathways for the lithium ions transfer, which validates our results further.

\section{Conclusions}

A promising $\mathrm{MnO} / \mathrm{PGA}$ hybrid anode material having hierarchical pore structure was synthesized by a novel site-localized nanoparticle-induced etching strategy. The high capacity, good cycling stability and excellent rate capability of MnO/PGA can be attributed to synergistic interactions between $\mathrm{MnO}$ particles and PGA. First, small MnO particles on the graphene sheets ranging from 50 to $100 \mathrm{~nm}$ are obtained through a site- localized nanoparticle-induced etching strategy. Second, the 3D conductive network composed of porous-graphene sheets can not only serve as multidimensional pathways to facilitate the transport of electrons and ions in the bulk electrode, but also provide abundant lithium-storage active sites due to more defects generated. Third, the space held up by 3D graphene framework and the nanopores on the graphene sheets relieve the inner stress caused by dramatic volume change of $\mathrm{MnO}$ during $\mathrm{Li}^{+}$insertion/extraction, leading to a long cycle lifetime. In conclusion, the combination of $\mathrm{PG}$ sheets and the $3 \mathrm{D}$ network framework play an unparalleled role to inspire the potential of $\mathrm{MnO}$ as a better anode material, which provide an effective approach to achieve superior lithium-storage properties.

\section{Acknowledgements}

This work was financially supported by the National Natural Science Foundation of China (Grant no. 21371176) and Key Research Program of the Chinese Academy of Sciences (Grant no. KGZD-EW-T08).

\section{Notes and references}

1 G. Yang, Y. Li, H. Ji, H. Wang, P. Gao, L. Wang, H. Liu, J. Pinto and X. Jiang, J. Power Sources, 2012, 216, 353-362.

2 Y. Qiu, G.-L. Xu, K. Yan, H. Sun, J. Xiao, S. Yang, S.-G. Sun, L. Jin and H. Deng, J. Mater. Chem., 2011, 21, 6346-6353.

3 S.-Y. Liu, J. Xie, Y.-X. Zheng, G.-S. Cao, T.-J. Zhu and X.-B. Zhao, Electrochim. Acta, 2012, 66, 271-278.

4 Y. Li, Q. Zhang, J. Zhu, X.-L. Wei and P. K. Shen, J. Mater. Chem. A, 2014, 2, 3163-3168.

5 K. Zhong, B. Zhang, S. Luo, W. Wen, H. Li, X. Huang and L. Chen, J. Power Sources, 2011, 196, 6802-6808.

6 C.-T. Hsieh, C.-Y. Lin and J.-Y. Lin, Electrochim. Acta, 2011, 56, 8861-8867.

7 S. M. Lee, S. H. Choi, J.-K. Lee and Y. C. Kang, Electrochim. Acta, 2014, 132, 441-447.

8 J. Zang, H. Qian, Z. Wei, Y. Cao, M. Zheng and Q. Dong, Electrochim. Acta, 2014, 118, 112-117.

9 T. Wu, F. Tu, S. Liu, S. Zhuang, G. Jin and C. Pan, J. Mater. Sci., 2013, 49, 1861-1867.

10 G. Zhao, X. Huang, X. Wang, P. Connor, J. Li, S. Zhang and J. T. S. Irvine, J. Mater. Chem. A, 2015, 3, 297-303.

11 K. Zhang, P. Han, L. Gu, L. Zhang, Z. Liu, Q. Kong, C. Zhang, S. Dong, Z. Zhang, J. Yao, H. Xu, G. Cui and L. Chen, ACS Appl. Mater. Interfaces, 2012, 4, 658-664.

12 Y. Sun, Q. Wu and G. Shi, Energy Environ. Sci., 2011, 4, 11131132.

13 S. Guo and S. Dong, Chem. Soc. Rev., 2011, 40, 2644-2672.

14 C. Xu, B. Xu, Y. Gu, Z. Xiong, J. Sun and X. S. Zhao, Energy Environ. Sci., 2013, 6, 1388-1414.

15 S. Zhang, L. Zhu, H. Song, X. Chen and J. Zhou, Nano Energy, 2014, 10, 172-180.

16 Y. Sun, X. Hu, W. Luo, F. Xia and Y. Huang, Adv. Funct. Mater., 2013, 23, 2436-2444. 
17 A. Yu, H. W. Park, A. Davies, D. C. Higgins, Z. Chen and X. Xiao, J. Phys. Chem. Lett., 2011, 2, 1855-1860.

18 Y. J. Mai, D. Zhang, Y. Q. Qiao, C. D. Gu, X. L. Wang and J. P. Tu, J. Power Sources, 2012, 216, 201-207.

19 D. Qiu, L. Ma, M. Zheng, Z. Lin, B. Zhao, Z. Wen, Z. Hu, L. Pu and Y. Shi, Mater. Lett., 2012, 84, 9-12.

20 M. Zheng, D. Qiu, B. Zhao, L. Ma, X. Wang, Z. Lin, L. Pan, Y. Zheng and Y. Shi, RSC Adv., 2013, 3, 699-703.

21 Z. Jian, B. Zhao, P. Liu, F. Li, M. Zheng, M. Chen, Y. Shi and H. Zhou, Chem. Commun., 2014, 50, 1215-1217.

22 Y. Xu, K. Sheng, C. Li and G. Shi, ACS Nano, 2010, 4324-4330.

23 B. Qiu, M. Xing and J. Zhang, J. Am. Chem. Soc., 2014, 136, 5852-5855.

24 W. Lv, C. Zhang, Z. Li and Q. H. Yang, J. Phys. Chem. Lett., 2015, 6, 658-668.

25 H.-K. Kim, S.-H. Park, S.-B. Yoon, C.-W. Lee, J. H. Jeong, K. C. Roh and K.-B. Kim, Chem. Mater., 2014, 26, 4838-4843.

26 L. Xiao, D. Wu, S. Han, Y. Huang, S. Li, M. He, F. Zhang and X. Feng, ACS Appl. Mater. Interfaces, 2013, 5, 3764-3769.

27 Z. S. Wu, S. Yang, Y. Sun, K. Parvez, X. Feng and K. Mullen, J. Am. Chem. Soc., 2012, 134, 9082-9085.

28 Y. Zhao, C. Hu, L. Song, L. Wang, G. Shi, L. Dai and L. Qu, Energy Environ. Sci., 2014, 1913-1918.
29 L. Jiang and Z. Fan, Nanoscale, 2014, 6, 1922-1945.

30 Y. Lin, K. A. Watson, J. W. Kim, D. W. Baggett, D. C. Working and J. W. Connell, Nanoscale, 2013, 5, 7814-7824.

31 X. Zhu, X. Song, X. Ma and G. Ning, ACS Appl. Mater. Interfaces, 2014, 6, 7189-7197.

32 Z. Fan, Q. Zhao, T. Li, J. Yan, Y. Ren, J. Feng and T. Wei, Carbon, 2012, 50, 1699-1703.

33 Y. Lin, X. Han, C. J. Campbell, J.-W. Kim, B. Zhao, W. Luo, J. Dai, L. Hu and J. W. Connell, Adv. Funct. Mater., 2015, 25, 2920-2927.

34 H. Cao, X. Zhou, W. Deng and Z. Liu, J. Mater. Chem. A, 2016, 4, 6021-6028.

35 X. Zhou and Z. Liu, Chem. Commun., 2010, 46, 2611-2613.

36 Y. Mao, H. Duan, B. Xu, L. Zhang, Y. Hu, C. Zhao, Z. Wang, L. Chen and Y. Yang, Energy Environ. Sci., 2012, 5, 7950-7955.

37 B. Sun, Z. Chen, H.-S. Kim, H. Ahn and G. Wang, J. Power Sources, 2011, 196, 3346-3349.

38 J. Guo, Q. Liu, C. Wang and M. R. Zachariah, Adv. Funct. Mater., 2012, 22, 803-811.

39 J. Gao, M. A. Lowe and H. C. D. Abruña, Chem. Mater., 2011, 23, 3223-3227. 